\title{
Effect of the 5-lipoxygenase inhibitor ZD2138 on aspirin-induced asthma
}

S M Shuaib Nasser, Gail S Bell, Steven Foster, Karen E Spruce, Roger MacMillan, Andrew J Williams, Tak H Lee, Jonathan P Arm

\section{Abstract}

Background - The cysteinyl leukotrienes may play a central part in the mechanisms of aspirin-sensitive asthma. Previous work has shown that individuals with aspirin-sensitive asthma have high basal urinary LTE $_{4}$ levels which increase further upon aspirin ingestion, and that sulphidopeptide leukotriene receptor antagonists attenuate aspirin-induced airflow obstruction. If the cysteinyl leukotrienes cause aspirin-induced asthmatic reactions, inhibition of the 5-lipoxygenase pathway should prevent aspirin-induced bronchospasm. This hypothesis has been tested with ZD2138, a specific non-redox 5-lipoxygenase inhibitor.

Methods - Seven subjects (four men) with aspirin-sensitive asthma with baseline $\mathrm{FEV}_{1}$ values $>67 \%$ were studied. $\mathrm{ZD2} 138$ (350 $\mathrm{mg}$ ) or placebo was given on two separate occasions two weeks apart in a randomised double blind fashion. A single dose of aspirin was administered four hours after dosing and $F_{1}$ was measured for six hours. Inhibition of the 5-lipoxygenase pathway by ZD2138 was assessed by measurements of urinary LTE $_{4}$ levels and ex vivo calcium ionophore stimulated $\mathbf{L T B}_{4}$ generation in whole blood, before administration of drug or placebo and at regular time intervals after dosing and aspirin administration.

Results - ZD2138 protected against the aspirin-induced reduction in $F E V_{1}$ with a $20.3(4.9) \%$ fall in $F^{2} V_{1}$ following placebo compared with $4.9 \quad(2.9) \%$ following ZD2138. This was associated with $72 \%$ inhibition of ex vivo $\mathrm{LTB}_{4}$ generation in whole blood at 12 hours and a $74 \%$ inhibition of the rise in urinary $\mathrm{LTE}_{4}$ excretion at six hours after aspirin ingestion.

Conclusions - In aspirin-sensitive asthma the 5-lipoxygenase inhibitor ZD2138 inhibits the fall in $F_{1}$ induced by aspirin and this is associated with substantial inhibition of 5-lipoxygenase.

\section{Zeneca}

Pharmaceuticals, Mereside, Macclesfield, Cheshire $S$ Foster

K E Spruce

R MacMillan

A J Williams

Reprint requests to: Professor T H Lee.

Received 6 October 1993 Returned to author 16 February 1994 Revised version received 18 April 1994 Accepted for publication 22 April 1994 nasal polyposis, rhinorrhoea, nasal congestion, anosmia with loss of taste, and frequent exacerbations of asthma. ${ }^{3-5}$

Arachidonic acid released from cell membrane phospholipids by phospholipase $\mathrm{A}_{2}$ may be further metabolised by the cyclooxygenase pathway to prostaglandins and thromboxane $\mathrm{A}_{2}$ or by the 5-lipoxygenase pathway to leukotrienes. ${ }^{6}$ The initial leukotriene formed by the action of 5-lipoxygenase is $\mathrm{LTA}_{4}$, which is then further metabolised by an epoxide hydrolase to $\mathrm{LTB}_{4}$ or by a glutathione S-transferase termed $\mathrm{LTC}_{4}$ synthase $^{7}$ to $\mathrm{LTC}_{4}$, which is further cleaved to $\mathrm{LTD}_{4}$ by gamma-glutamyl transpeptidase and to $\mathrm{LTE}_{4}$ by a dipeptidase. The cysteinyl leukotrienes $\mathrm{LTC}_{4}, \mathrm{LTD}_{4}$, and $\mathrm{LTE}_{4}$ are potent spasmogens for airway smooth muscle $^{8}$ and comprise the activity previously recognised as slow reacting substance of anaphylaxis. ${ }^{9}$

The mechanism of aspirin-sensitive asthma remains unresolved, but it is known that the ability of drugs to cause symptoms in aspirinsensitive asthma is related to their potency as cyclooxygenase inhibitors. ${ }^{10}$ It has been proposed that blockade of cyclooxygenase activity by these agents leads to diversion of arachidonic acid metabolism from the cyclooxygenase to the 5-lipoxygenase pathway with consequent increased leukotriene production. ${ }^{11}$ The evidence for the involvement of the cysteinyl leukotrienes in aspirin-sensitive asthma is compelling. Subjects with aspirin-sensitive asthma have six times higher basal levels of urinary $\mathrm{LTE}_{4}$ than aspirin-tolerant asthmatic and nonasthmatic subjects. ${ }^{12}$ Furthermore, aspirin challenge of subjects with aspirin-sensitive asthma, which leads to bronchoconstriction, is accompanied by a mean fourfold increase in urinary $\mathrm{LTE}_{4}$ excretion. ${ }^{12}$ No clinical symptoms or increase in urinary $\mathrm{LTE}_{4}$ levels are detected in non-aspirin-sensitive asthmatic individuals following aspirin ingestion. Additionally, there is increased target organ sensitivity to the bronchospastic effects of inhaled $\mathrm{LTE}_{4}$ in subjects with aspirin-sensitive asthma compared with aspirin-tolerant asthmatic subjects. ${ }^{13}$ Previous studies have shown the efficacy of cysteinyl leukotriene receptor antagonists in the mechanisms of aspirin-sensitive asthma. ${ }^{1415}$ If leukotrienes are critical in the asthmatic response provoked by aspirin, one might expect an inhibitor of 5-lipoxygenase to block aspirin-sensitive asthma. We have tested this hypothesis with ZD2138, a novel non-redox lipoxygenase inhibitor ${ }^{16}$ which is well tolerated and, at single oral doses of $350 \mathrm{mg}$ or greater, inhibits ex vivo $\mathrm{LTB}_{4}$ synthesis in whole blood for 24 hours. ${ }^{17}$ 


\section{Methods}

SUBJECTS

Seven non-smoking subjects (three women) of mean age 42 (range 35-52) years with aspirinsensitive asthma were studied (table 1). Their resulting mean (SE) forced expiratory volume in one second $\left(\mathrm{FEV}_{1}\right)$ was $2.57(0.17) 1$ (mean predicted $86 \%$; range $67-105 \%$ ). All subjects also suffered with symptoms of rhinosinusitis comprising nasal congestion, rhinorrhoea, and varying degrees of dysosmia and loss of taste. The study was approved by the Guy's Hospital ethics committee and written informed consent was obtained from each subject.

\section{STUDY PROTOCOI}

Subjects were screened for aspirin sensitivity if they had a history of worsening asthma on aspirin ingestion. They were studied on three days, each separated by two weeks. On day 1 a medical history was taken and the subjects underwent general physical examination with an ECG. Blood was taken for a full blood count, clotting studies, estimation of electrolytes and urea, and liver function tests. Urine was examined by microscopy and tested for glucose, protein, and blood. Oral aspirin challenge was then performed with incremental doses of aspirin at two-hourly intervals, starting with $30 \mathrm{mg}$. The dose of aspirin resulting in a $20 \%$ or greater fall in $\mathrm{FEV}_{1}$ within two hours of ingestion was considered the threshold dose and used on days 2 and 3 .

On days 2 and $3350 \mathrm{mg}$ ZD2138 (Zeneca Pharmaceuticals, Macclesfield, Cheshire, UK) or matching placebo was given after an overnight fast in a randomised, double blind fashion. Four hours later aspirin challenge was performed with the threshold dose as determined on day 1. Continuous ambulatory ECG was monitored on days 2 and 3 for 24 hours. Urine was collected before drug or placebo administration and then immediately before and three, six, and nine hours after aspirin challenge. Blood for determination of ex vivo $\mathrm{LTB}_{4}$ generation was taken before and four (pre-aspirin), 12, and 24 hours after drug or placebo administration.

\section{SPIROMETRY AND ASPIRIN CHALLENGE}

Two recordings of $\mathrm{FEV}_{1}$ were made with a dry wedge bellows spirometer (Vitalograph Ltd, Buckingham, UK) at each time point and the highest value was used. Aspirin was prepared in

Table 1 Baseline FEV, values, medication, and threshold dose of aspirin in the seven subjects

\begin{tabular}{llllclc}
\hline Subject & $\begin{array}{l}\text { Age } \\
\text { (years) }\end{array}$ & Sex & $\begin{array}{l}\text { FEV } \\
\text { (litres) }\end{array}$ & $\begin{array}{l}\% \text { predicted } \\
F E V_{1}\end{array}$ & Drugs & $\begin{array}{l}\text { Aspirin } \\
\text { dose }(m g)\end{array}$ \\
\hline 1 & 37 & M & $2 \cdot 46$ & 67 & S, B & 30 \\
2 & 44 & F & $2 \cdot 29$ & 85 & S & 30 \\
3 & 35 & M & $3 \cdot 40$ & 91 & S, B & 60 \\
4 & 35 & F & $2 \cdot 24$ & 89 & S, B, nB & 40 \\
5 & 48 & M & $3 \cdot 04$ & 82 & S, B, nF & 60 \\
6 & 46 & M & $2 \cdot 28$ & 81 & Bu, nB, T & 100 \\
7 & 52 & F & $2 \cdot 29$ & 105 & Bu, Tn & 60 \\
\hline
\end{tabular}

$\mathrm{S}=$ salbutamol; $\mathrm{B}=$ beclomethasone dipropionate; $\mathrm{Bu}=$ budesonide; $\mathrm{T}=$ terfenadine; $\mathrm{T} \mathrm{n}=$ terbuta line; $\mathrm{nB}=$ nasal beclomethasone; $\mathrm{nF}=$ nasal fluticasone. gelatin capsules of 10,30 , and $100 \mathrm{mg}$ by the Guy's Hospital pharmacy. On study day 1 screening for aspirin sensitivity by aspirin challenge was performed. The starting dose of aspirin was $30 \mathrm{mg}$, after which measurements of $\mathrm{FEV}_{1}$ were made at 15 minute intervals for two hours. The challenge was stopped if the $\mathrm{FEV}_{1}$ had fallen by $20 \%$ or more within this time. If the fall was less than $20 \%$ and the subject was within $10 \%$ of baseline $\mathrm{FEV}_{1}$, further incremental doses of aspirin were given in the order $60,100,300$, and $600 \mathrm{mg}$ at two-hourly intervals. A fall in $\mathrm{FEV}_{1}$ of between $10 \%$ and $20 \%$ was allowed to return to within $10 \%$ of baseline before the next dose was administered. The dose that elicited a fall in $\mathrm{FEV}_{1}$ of $20 \%$ or more was considered the threshold dose. On study days 2 and 3 the threshold dose of aspirin was administered four hours after dosing with

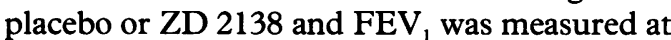
15 minute intervals for two hours and then hourly until six hours after aspirin administration. All subjects were asked to report any new symptoms or change in symptoms after aspirin ingestion from the baseline period and these were recorded. Antihistamines were discontinued for 48 hours, inhaled and nasal corticosteroids for 24 hours, and salbutamol for at least eight hours before each study day until 24 hours after aspirin challenge.

\section{MEASUREMENT OF URINARY LTE $_{4}$}

The free radical scavenger 4-hydroxy-2,2,6,6tetramethylpiperidinooxy free radical (4-hydroxy-TEMPO; Sigma Chemical Company, Poole, Dorset, UK) was added to each urine sample immediately after collection to a final concentration of $1 \mathrm{mmol} / \mathrm{l}$, the samples were adjusted to $\mathrm{pH} 9$ with $\mathrm{NaOH}$ to stabilise endogenous leukotriene metabolites and stored at $-70^{\circ} \mathrm{C}$ until analysed. Urinary $\mathrm{LTE}_{4}$ levels were measured as described previously. ${ }^{18}$ The stored urine samples were thawed and $50 \mu$ of a solution containing $\left[{ }^{3} \mathrm{H}\right] \mathrm{LTE}_{4}(128.5 \mathrm{Ci} / \mathrm{mmol}$; NEN, DuPont, Boston, USA) was added to $10 \mathrm{ml}$ urine to give 4000 disintegrations per minute. After adding $250 \mu \mathrm{l}$ glacial acetic acid to bring the $\mathrm{pH}$ to $3 \cdot 5-3 \cdot 8$ the $10 \mathrm{ml}$ sample was loaded onto a $10 \mu \mathrm{m}$ precolumn (Ultrasil ODS, $3.4 \mathrm{~mm} \times 4.5 \mathrm{~cm}$, Beckman, USA) to wash off polar metabolites with a phosphate buffer $\left(0.1 \% \mathrm{NaH}_{2} \mathrm{PO}_{4}, \mathrm{pH} 3.8\right)$ for eight minutes and then for 12 minutes with methanol:phosphate buffer in the proportions 50:50 (v:v). The sample was then retrogradely eluted onto a reversed phase analytical column (Ultrasil ODS $4.5 \mathrm{~mm} \times 25 \mathrm{~cm}$, Altex) that had been equilibrated in $62 \%$ methanol: $37.8 \%$ water: $0 \cdot 1 \%$ acetic acid:0.1\% EDTA (v:v:v:w) at pH 5.6 at a flow rate of $1 \mathrm{ml} / \mathrm{min}$. One minute fractions were collected and the fraction containing peak radioactivity corresponding to the internal standard was identified by counting $250 \mu$ l of the eluent in a $\beta$ liquid scintillation counter (Tricarb 1900CA, Packard Instrument Co, USA). The remaining $750 \mu l$ of those fractions containing $\left[{ }^{3} \mathrm{H}\right] \mathrm{LTE}_{4}$ and the two fractions eluted before and after the peak were dried under vacuum and resuspended in $250 \mu \mathrm{l}$ of 
$10 \mathrm{mmol} / \mathrm{l}$ Tris $\mathrm{HCl}$ buffer $(\mathrm{pH} 7 \cdot 4)$. The concentration of immunoreactive $\mathrm{LTE}_{4}$ was assessed by radioimmunoassay as described previously. ${ }^{19}$ Urinary creatinine concentrations were measured (Mira Analyser, Hoffman Roche, Welwyn) by the kinetic picrate method, without deproteinisation. ${ }^{20} \mathrm{LTE}_{4}$ concentrations were expressed as $\mathrm{pg} / \mathrm{mg}$ creatinine and were calculated from measured immunoreactivity minus background, corrected for recovery and dilution.

MEASUREMENT OF EX VIVO $\mathrm{LTB}_{4}$

The ability of ZD2138 to inhibit 5-lipoxygenase was also assessed by measurement of calcium ionophore-stimulated ex vivo $\mathrm{LTB}_{4}$ production in whole blood. Blood was collected into heparinised tubes and calcium ionophore (A23187) added to $500 \mu \mathrm{l}$ whole blood in triplicate to a final concentration of $2.5 \mu \mathrm{mol} / 1$. The blood was incubated for 20 minutes at $37^{\circ} \mathrm{C}$, centrifuged at $3600 \mathrm{rpm}$ for one minute, and the supernatant stored at $-20^{\circ} \mathrm{C}$. $\mathrm{LTB}_{4}$ was assayed subsequently by radioimmunoassay, as previously described. ${ }^{21}$

DATA ANALYSIS

The area under the $\mathrm{FEV}_{1}$-time curve following administration of placebo or ZD2138 was calculated for the four hours before aspirin challenge to assess bronchodilatation and for the six hours after aspirin challenge and analysed nonparametrically by the Wilcoxon signed rank test. Using linear regression analysis, the percentage inhibition of urinary $\mathrm{LTE}_{4}$ was correlated with the degree of protection by ZD2138 against a fall in FEV for each of the periods $-4-0,0-2$, and 2-6 hours after aspirin ingestion. Baseline $\mathrm{FEV}_{1}$ and urinary $\mathrm{LTE}_{4}$ values were also correlated with the degree of bronchodilatation in each individual using linear regression analysis. The urinary $\mathrm{LTE}_{4}$ values were expressed as $\mathrm{pg} / \mathrm{mg}$ creatinine and the area under the urinary $\mathrm{LTE}_{4}$-time curve for the drug and placebo days were also compared using the Wilcoxon signed rank test. Data for $\mathrm{LTB}_{4}$ values were only available for five of the seven subjects because of technical difficulties with the other samples. All data points are expressed as mean (SE).

Table 2 Symptoms related to aspirin ingestion after premedication with placebo or ZD2138

\begin{tabular}{lll}
\hline Subject & Placebo day & ZD2138 day \\
\hline 1 & $\begin{array}{l}\text { Rhinorrhoea, conjunctival } \\
\text { streaming, wheeze }\end{array}$ & - \\
2 & $\begin{array}{l}\text { Wheeze, sneezing } \\
\text { Rhinorrhoea, epigastric } \\
\text { discomfort, wheeze }\end{array}$ & - \\
3 & $\begin{array}{l}\text { Nausea, vomiting, } \\
\text { headache, wheeze } \\
\text { Wheeze }\end{array}$ & Nausea, headache \\
4 & $\begin{array}{l}\text { Nasal congestion, severe } \\
\text { fatigue, nausea, chest } \\
\text { pain, wheeze } \\
\text { Wheeze, rhinorrhoea, } \\
\text { sneezing, headache }\end{array}$ & $\begin{array}{l}\text { Rhinorrhoea, } \\
\text { conjunctival streaming, } \\
\text { tiredness }\end{array}$ \\
6 & - \\
\hline
\end{tabular}

Results

SUBJECTS

On the screening day all subjects experienced symptoms of wheeze following aspirin ingestion and, in addition, subjects $1,2,3,6$, and 7 experienced rhinorrhoea and nasal congestion. Table 2 describes the symptoms experienced by the subjects on the study days. In all subjects ZD2138 premedication reduced aspirininduced symptoms.

\section{AIRWAY RESPONSES}

The resting $\mathrm{FEV}_{1}$ before drug administration was significantly lower on the ZD2138 day $(2.361)$ than on the placebo day $(2 \cdot 71 ; \mathrm{p}<0.05)$. Figure 1 shows the mean change in $\mathrm{FEV}_{1}$ for four hours after administration of placebo or $\mathrm{ZD} 2138 . \mathrm{FEV}_{1}$ rose by $7(2 \cdot 3) \%$ at three hours after administration of ZD2138 compared with a fall of $4(3.9) \%$ after placebo $(p<0.05)$. The mean $\mathrm{FEV}_{1}$ at four hours after drug/placebo administration and immediately before aspirin challenge was $2.43(0 \cdot 16) 1$ after ZD2138 and $2.57(0.17) 1$ after placebo $(p>0.05)$. There was no correlation between the degree of bronchodilatation and baseline $\mathrm{FEV}_{1}$, baseline urinary $\mathrm{LTE}_{4}$, or asthma medication.

There was overall protection by ZD2138 of the fall in $\mathrm{FEV}_{1}$ induced by aspirin challenge $(p=0.05)$ as shown in fig 2 . On the placebo day

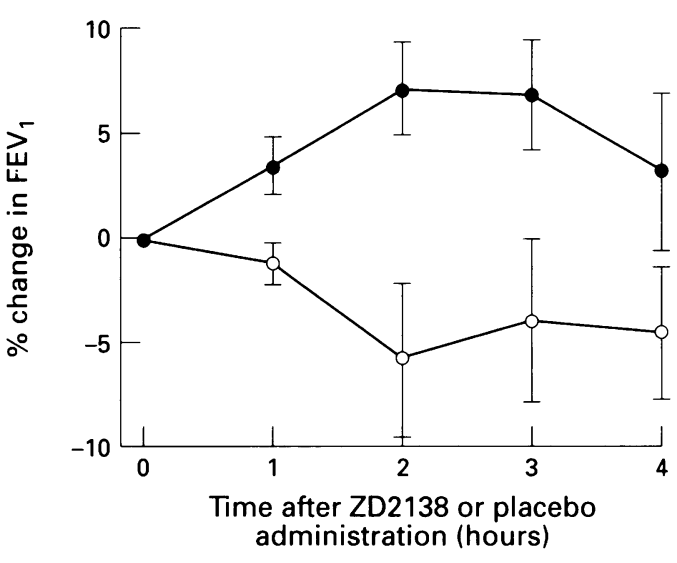

Figure 1 Percentage change in FEV, for the four hours after administration of ZD2138 ( ) or placebo $(O)$, and before aspirin challenge.

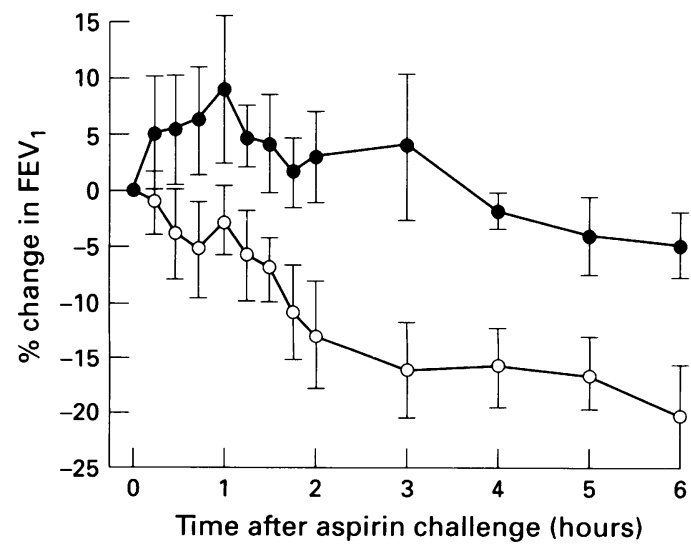

Figure 2 Mean (SE) percentage change in $F E V_{1}$ for six hours after aspirin challenge. ZD2138 (O) or placebo ( $)$ was administered four hours before aspirin challenge. 
Table 3 Maximum change in FEV, for each of the seven subjects during the periods $0-2$ and 2-6 hours

\begin{tabular}{|c|c|c|c|c|c|c|}
\hline \multirow[t]{2}{*}{ Subject } & \multicolumn{2}{|l|}{$0-2$ hours } & \multicolumn{2}{|l|}{$2-6$ hours } & \multicolumn{2}{|l|}{ Evaluation } \\
\hline & $P$ & $D$ & $P$ & $D$ & $0-2$ hours & 2-6 hours \\
\hline $\begin{array}{l}1 \\
2 \\
3 \\
4 \\
5 \\
6 \\
7 \\
\text { Mean (SE) }\end{array}$ & $\begin{array}{l}-10 \\
-12 \\
-36 \\
+5 \\
-22 \\
-10 \\
-15 \\
-14(5)\end{array}$ & $\begin{aligned} & 0 \\
+ & 2 \\
+ & 18 \\
- & 7 \\
& 0 \\
-9 & \\
& 0 \\
& 0 \cdot 6(3)\end{aligned}$ & $\begin{array}{l}-11 \\
-25 \\
-47 \\
-15 \\
-17 \\
-17 \\
-18 \\
-21(6)\end{array}$ & $\begin{array}{l}-8 \\
-9 \\
+7 \\
-10 \\
+2 \\
-19 \\
-10 \\
-7(3)\end{array}$ & $\begin{array}{l}\mathrm{R} \\
\mathrm{R} \\
\mathrm{R} \\
\mathrm{NE} \\
\mathrm{R} \\
\mathrm{NR} \\
\mathrm{R}\end{array}$ & $\begin{array}{l}\text { NR } \\
\text { R } \\
\text { R } \\
\text { PR } \\
\text { R } \\
\text { NR } \\
\text { PR }\end{array}$ \\
\hline
\end{tabular}

Based on the fall in $\mathrm{FEV}_{1}$ and the difference between drug $(\mathrm{D})$ and placebo $(\mathrm{P})$ days, each subject has been categorised as a responder (R), partial responder (PR), or non-responder (NR) to ZD2138. $\mathrm{NE}=$ non-evaluable.
$806(369) \mathrm{pg} / \mathrm{mg}$ creatinine at three hours, 1853 (986) $\mathrm{pg} / \mathrm{mg}$ creatinine at six hours, and 1743 (482) $\mathrm{pg} / \mathrm{mg}$ creatinine at nine hours after aspirin challenge. After administration of ZD2138 there was a fall in urinary $\mathrm{LTE}_{4}$ levels in all seven subjects from a baseline value of 402 (100) $\mathrm{pg} / \mathrm{mg}$ creatinine to 180 (47) $\mathrm{pg} / \mathrm{mg}$ creatinine immediately before aspirin challenge $(\mathrm{p}<0.05)$. The urinary $\mathrm{LTE}_{4}$ concentration was $275(181) \mathrm{pg} / \mathrm{mg}$ creatinine at three hours, $487(405) \mathrm{pg} / \mathrm{mg}$ creatinine at six hours, and 713 (573) $\mathrm{pg} / \mathrm{mg}$ creatinine at nine hours after aspirin challenge. Compared with placebo there was $43 \%$ inhibition at four hours, $70 \%$ at seven hours, $74 \%$ at 10 hours, and $59 \%$ at 13 hours after dosing with ZD2138. Significantly less urinary $\mathrm{LTE}_{4}$ excretion was seen after ZD2138 than after administration of placebo $(p<0.05)$.

ZD2138 was well tolerated and no adverse events attributed to the drug occurred in the study. All seven subjects completed the study.

(4.9)\% six hours after administration of compared with $4.9(2.9) \%$ on the ZD2138 day. Individual data are shown in fig 3. In subjects 3 and 5 there was complete inhibition and in subjects 1,2 , and 7 there was partial protection of the aspirin-induced asthmatic reaction. In subject 4 there was no inhibitory effect of the 5lipoxygenase inhibitor on aspirin-provoked bronchoconstriction.

The effects of ZD2138 on aspirin-induced responses are similarly apparent if the maximal falls in $\mathrm{FEV}_{1}$ in the first two hours and for the $2-6$ hour period are analysed. In the first two hours five of the seven individuals clearly showed attenuation of the aspirin-induced response by active drug. Subject 4 could not be evaluated during the first two hours because she did not have a significant fall in $\mathrm{FEV}_{1}$. Similarly, for the 2-6 hour period five of the seven individuals showed a response (table 3 ).

There was no significant correlation between inhibition of urinary $\mathrm{LTE}_{4}$ levels and protection by ZD2138 against a fall in $\mathrm{FEV}_{1}$ induced by aspirin for the periods $-4-0$ hours $(r=0.37$; $\mathrm{p}<0.5), 0-2$ hours $(r=0.43 ; \mathrm{p}<0.5)$, and $2-6$ hours $(r=0.3 ; \mathrm{p}=0.5)$ after aspirin ingestion.

INHIBITION OF EX VIVO GENERATION OF LTB Figure 4 shows the mean ionophore-induced generation of $\mathrm{LTB}_{4}$ from whole blood after administration of placebo and ZD2138. The baseline $\mathrm{LTB}_{4}$ levels were $102 \cdot 4(30) \mu \mathrm{g} / \mathrm{ml}$ and $97 \cdot 1(26) \mu \mathrm{g} / \mathrm{ml}$ on the $\mathrm{ZD} 2138$ and placebo days, respectively. There was substantial inhibition of ex vivo generation of whole blood $\mathrm{LTB}_{4}$; compared with placebo there was an average $57 \%$ inhibition at four hours, $72 \%$ inhibition at 12 hours, and $76 \%$ at 24 hours after dosing with ZD2138.

URINARY $\mathrm{LTE}_{4}$

There was no significant difference between baseline urinary $\mathrm{LTE}_{4}$ levels on the two days (fig 5). On the placebo day urinary $\mathrm{LTE}_{4}$ levels did not change significantly from the baseline value of 391 (72) $\mathrm{pg} / \mathrm{mg}$ creatinine to 319 (64) $\mathrm{pg} / \mathrm{mg}$ creatinine at four hours after placebo administration immediately before aspirin challenge $(p<0 \cdot 05) . \mathrm{LTE}_{4}$ excretion increased to

\section{Discussion}

The ability of ZD2138 to modulate aspirininduced asthma has been investigated in seven asthmatic subjects with aspirin sensitivity. ZD2138 is a novel non-redox 5-lipoxygenase inhibitor which is derived from a unique enantioselective series. It is well tolerated and at single oral doses of $350 \mathrm{mg}$ or more inhibits leukotriene synthesis for 24 hours. ${ }^{17}$ The drug was given to fasted subjects to standardise bioavailability. The study was designed so that aspirin provocation was undertaken four hours after drug administration when the plasma level of the drug is anticipated to be maximal. Changes in pulmonary function were measured using $\mathrm{FEV}_{1}$, and the effectiveness of 5-lipoxygenase inhibition was assessed by measuring $\mathrm{LTB}_{4}$ generation of calcium ionophore-activated whole blood leucocytes and excretion of immunoreactive $\mathrm{LTE}_{4}$ into the urine.

We have shown that 5-lipoxygenase inhibition by ZD2138 leads to significant bronchodilatation and protection against the fall in $\mathrm{FEV}_{1}$ induced by oral aspirin challenge in individuals with aspirin-sensitive asthma. In addition, each patient experienced significantly fewer naso-ocular and/or systemic symptoms in response to aspirin after dosing with ZD2138 compared with placebo. The reduction in systemic symptoms was observed even in the individual who showed no amelioration of the decrement in $\mathrm{FEV}_{1}$ following aspirin ingestion after premedication with the active drug (subject 4$)$.

The heterogeneity of $\mathrm{FEV}_{1}$ responses to the inhibitory effects of antileukotriene drugs has been reported previously. ${ }^{14}$ This may reflect heterogeneity of mechanisms for aspirin-sensitive asthma, inadequate 5-lipoxygenase inhibition in some individuals, or involvement of other mediators in the bronchoconstriction produced by aspirin-sensitive asthma. In this regard, naso-ocular symptoms induced by either oral aspirin or inhaled lysine-aspirin are associated with histamine release into nasal lavage fluid. ${ }^{22} 23$ Bosso et al recently reported that histamine and tryptase release in venous blood 

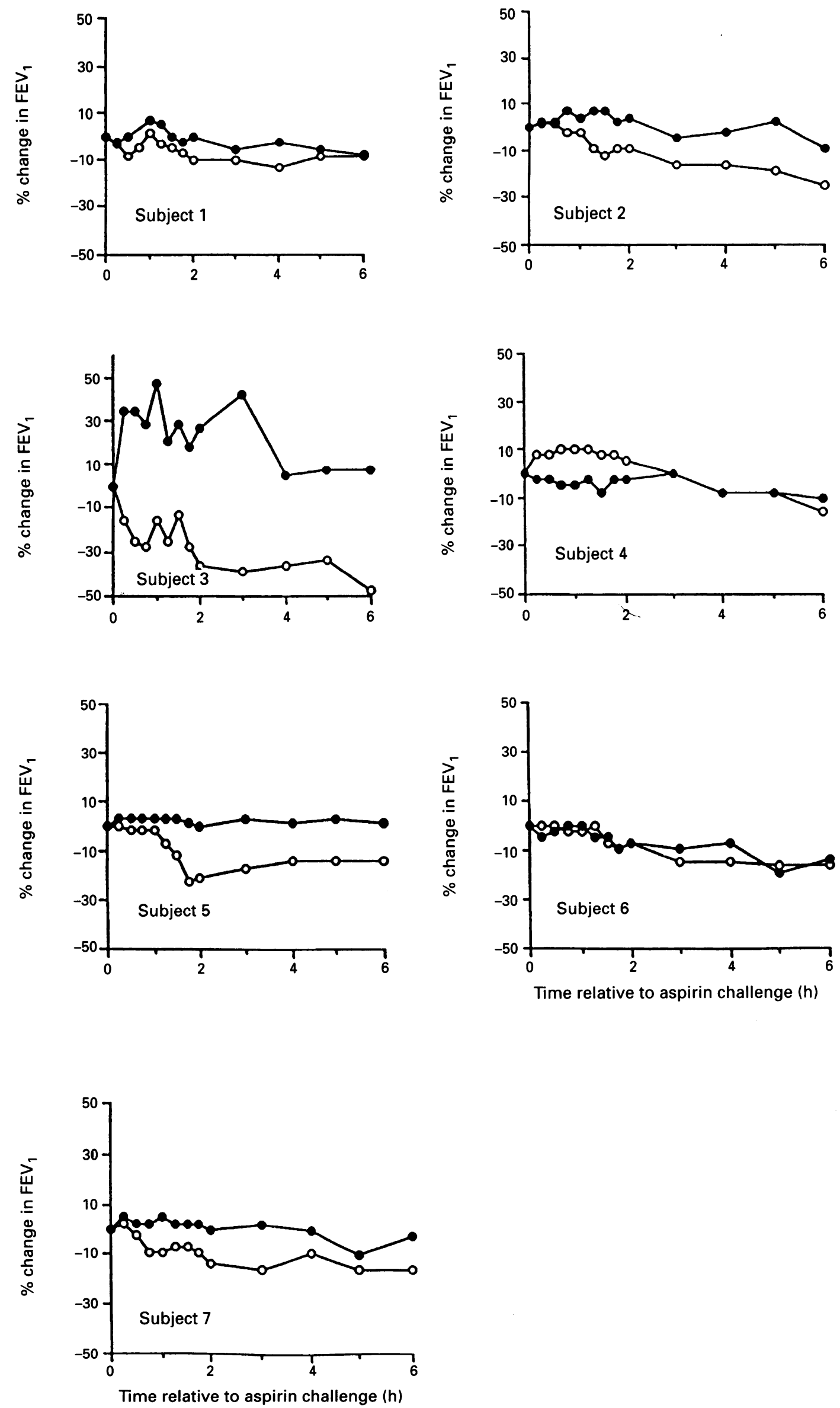

Figure 3 Individual graphs for all seven subjects demonstrating the percentage change in FEV, for six hours following aspirin challenge. $Z D 2138()_{1}$ ) or placebo $(O)$ was administered four hours before aspirin challenge. 


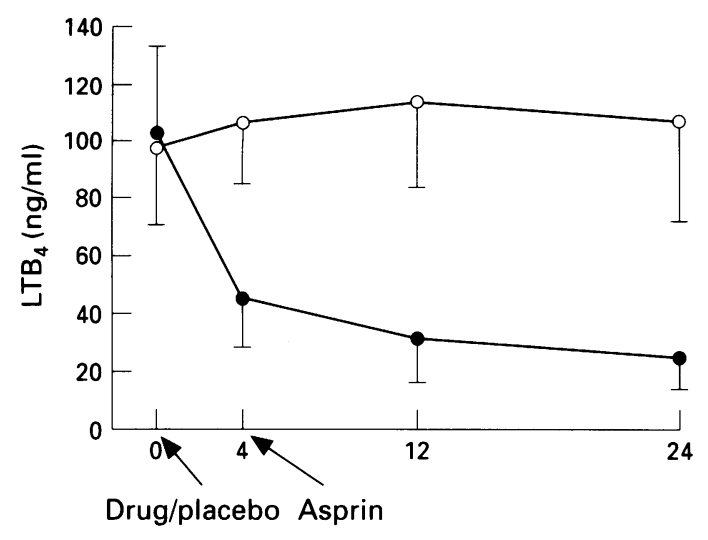

Time after ZD2138 or placebo administration (hours)

Figure 4 Mean ( $S E$ ) whole blood ex vivo $\mathrm{LTB}_{4}$ generation in response to $2.5 \mathrm{\mu mol} / \mathrm{l}$ A23187 for five of the seven subjects'before and after receiving ZD2138 (O or placebo $(\bigcirc)$. Aspirin was administered immediately after the four hour time point. The data for two subjects are not shown because of technical difficulties in analysis of samples.

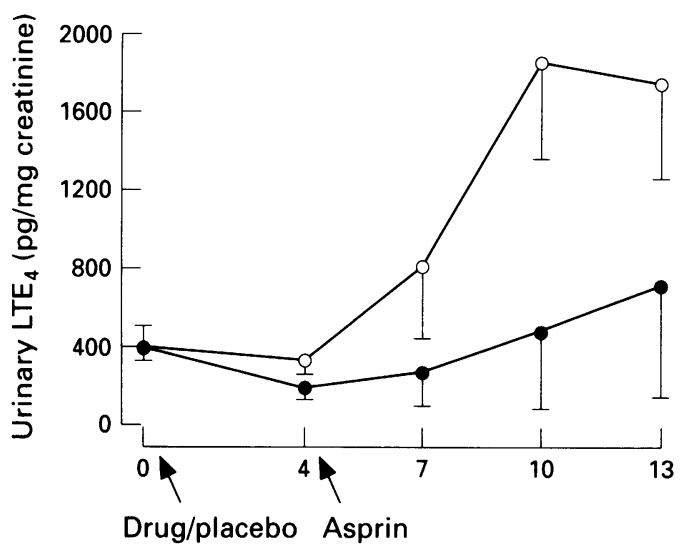

Time after ZD2138 or placebo administration (hours)

Figure 5 Mean ( $S E$ ) urinary $L T E_{4}$ levels for the seven subjects before and after receiving ZD2138 (O) or placebo (O). Aspirin was administered four hours after dosing.

samples occurred in three out of four aspirinsensitive asthmatic subjects following aspirin challenge. These three subjects experienced bronchospasm which was accompanied by gastrointestinal and/or skin reactions. There was no increase in tryptase in the remaining patients who developed bronchospasm but did not experience extrapulmonary symptoms. ${ }^{24}$

In all subjects ZD2138 inhibited the production of $\mathrm{LTB}_{4}$ by whole blood leucocytes stimulated by calcium ionophore, and this inhibitory activity was present for 24 hours. There was a significant rise in urinary $\mathrm{LTE}_{4}$ excretion in all patients following aspirin ingestion on the placebo day. ZD2138 completely attenuated the rise in urinary $\mathrm{LTE}_{4}$ excretion in all but one subject (subject 6) in whom no difference was seen between the two study days. Thus, there may have been incomplete attenuation of 5-lipoxygenase, accounting for the relative ineffectiveness of the drug in attenuating the pulmonary response to aspirin-sensitive asthma in this individual. Ex vivo $\mathrm{LTB}_{4}$ generation was inhibited by $51 \%, 38 \%$, and $68 \%$ at four, 12 , and 24 hours in this individual, however, thereby emphasising possible discordance in the different assays for demonstrating in vivo 5lipoxygenase inhibition and their relevance to clinical efficacy. In subject 4 there was a substantial increase in urinary $\mathrm{LTE}_{4}$ levels following ingestion of aspirin on the placebo day which was completely inhibited by ZD2138. These observations suggest that the lack of response to ZD2138 in this subject was unlikely to be due to inadequate 5-lipoxygenase inhibition. The possibility that the drug did not reach adequate concentrations locally in the airways cannot be excluded.

The increase in airway calibre following administration of ZD2138 is compatible with the reported effects of another 5-lipoxygenase inhibitor, Zileuton, ${ }^{25}$ and leukotriene antagonists, ${ }^{2627}$ on increasing airway calibre in asthmatic subjects. However, the results of the present study are confounded by the fact that the baseline $\mathrm{FEV}_{1}$ before drug administration was significantly lower than that on the placebo day. The data may therefore be a statistical artefact and simply represent a regression towards the mean. Further studies are needed to define whether there is any significant effect of the active drug on the calibre of resting airways. In a previous study of the effects of ZD2138 on allergen challenge, drug administration did not increase baseline $\mathrm{FEV}_{1}$ values. The asthmatic subjects in that study, however, had milder asthma and their resting $\mathrm{FEV}_{1}$ was almost normal. ${ }^{28}$

The time-dependent decreases in $\mathrm{FEV}_{1}$ following aspirin ingestion on the placebo day in this study were more prolonged than those reported previously. A notable difference between the present study and the earlier reports is that aspirin was administered just before food ingestion in the present investigation. It is therefore possible that food delayed aspirin absorption and the subsequent decrease in $\mathrm{FEV}_{1}$. Future studies should consider using inhaled lysine-aspirin challenge to provoke asthma in aspirin-sensitive individuals to avoid interactions with food.

The mechanism of aspirin-sensitive asthma is incompletely understood. Although there is considerable evidence to suggest that cyclooxygenase inhibition increases $\mathrm{LTC}_{4}$ synthesis in aspirin-sensitive asthmatic subjects, there is little evidence to suggest that this occurs as a result of diversion from the cyclooxygenase pathway to the 5-lipoxygenase at the relatively low doses of aspirin required to induce the response. The finding that pretreatment of sensitised human airways in vitro with indomethacin results in increased generation of $\mathrm{LTC}_{4}$ following IgE-dependent challenge supports the view that cyclooxygenase inhibition augments increased leukotriene release. ${ }^{29} \mathrm{Simi}$ larly, in the guinea pig model of antigeninduced anaphylaxis, pretreatment of animals with indomethacin results in an enhancement of 
the pulmonary mechanical response to intravenous antigen which is accompanied by an increased generation of $\mathrm{LTB}_{4} \cdot{ }^{30}$ Studies in humans with aspirin sensitivity also indicate that increased generation of leukotrienes may contribute to the mechanisms of aspirin-sensitive asthma. Ferreri et al found that, in patients who developed naso-ocular symptoms following ingestion of aspirin, concentrations of both $\mathrm{LTC}_{4}$ and histamine from nasal lavage fluid increased significantly from baseline values after provocation. ${ }^{22}$ There was no decrease in $\mathrm{PGE}_{2}$ after administration of the low doses of aspirin required to induce the response. Intranasal challenge with lysine-aspirin also led to increased nasal concentrations of histamine and $\mathrm{LTC}_{4}$ in aspirin-sensitive subjects, but not in aspirin-tolerant individuals. ${ }^{23}$ Urinary concentrations of $\mathrm{LTE}_{4}$ have been used to reflect systemic synthesis of $\mathrm{LTC}_{4}$ following both oral challenge with aspirin and bronchial challenge with inhaled lysine-aspirin. Christie et al reported that ingestion of aspirin which produced a $>15 \%$ fall in $\mathrm{FEV}_{1}$ was associated with a mean fourfold increase in urinary $\mathrm{LTE}_{4}$. Placebo challenge for the same individuals and aspirin challenge in asthmatic subjects tolerant of aspirin were not associated with a change in $\mathrm{FEV}_{1}$ or increments in urinary $\mathrm{LTE}_{4}$ concentration. ${ }^{12}$ These observations were confirmed in subsequent reports. ${ }^{31}{ }^{32}$ Christie et $a l^{33}$ and Dahlen $e t ~ a l^{34}$ have also reported significant rises in urinary $\mathrm{LTE}_{4}$ following bronchial challenge with lysine-aspirin.

In contrast to the present study ZD2138 did not protect against allergen-induced asthma. ${ }^{28}$ The designs of the allergen and aspirin challenge studies were identical and the dose of ZD2138 used in both studies was the same. This suggests that the mechanisms for allergenand aspirin-induced bronchoconstrictions are different. Aspirin-induced asthma appears to be more dependent on 5-lipoxygenase pathway metabolites. This is supported by our previous finding that asthmatic patients with aspirin sensitivity have higher basal levels of $\mathrm{LTE}_{4}$ excretion in the urine than asthmatic patients without aspirin sensitivity, ${ }^{12} 18$ and the observation that subjects with aspirin-sensitive asthma are considerably more sensitive to the bronchoconstrictor effects of inhaled $\mathrm{LTE}_{4}$ than aspirin-tolerant asthmatic subjects. ${ }^{13}$ Aspirininduced asthma may therefore be a more pertinent in vivo model for assessing the preliminary therapeutic efficacy of this class of novel drug than allergen challenge. Our findings emphasise the importance of choosing the correct model when testing the efficacy of new therapeutic agents in man.

MK886, a FLAP inhibitor, has been shown to inhibit allergen-induced bronchospasm ${ }^{35}$ Neither ZD2138 ${ }^{28}$ nor Zileuton ${ }^{36}$ inhibited allergen-induced bronchospasm, but both protected against aspirin-induced falls in $\mathrm{FEV}_{1}{ }^{37} \mathrm{It}$ remains to be evaluated whether different classes of 5-lipoxygenase inhibitors exhibit heterogeneity in clinical efficacy. The present study is consistent with a significant role for leukotrienes in the mechanisms contributing to aspirin-sensitive asthma, since inhibition of 5- lipoxygenase by ZD2138 led to a substantial attenuation of the pulmonary response to aspirin in these patients.

This study was supported by the National Asthma Campaign.

1 Stevenson DD, Mathison DA, Tan EM, Vaughan JH. Provoking factors in bronchial asthma. Arch Intern Med Provoking factor

2 Spector SL, Wangurod CH, Farr RS. Aspirin and concomitant idiosyncrasies in adult asthmatic patients. $\mathcal{F}$ Allergy Clin Immunol 1979;64:500-5.

3 Samter M, Biers RF. Intolerance to aspirin: clinical studies and consideration of its pathogenesis. Ann Intern Med 1968;6:975-83.

4 McDonald JR, Mathison DA, Stevenson DD. Aspirin intolerance in asthma: detection by oral challenge. $\mathcal{f}$ Allergy lerance in asthma: detection by

5 Lumry WR, Curd JG, Stevenson DD. Aspirin-sensitive asthma and rhino-sinusitis: current concepts and recent advances. Ear Nose Throat $\mathcal{f}$ 1984;63:66-70.

6 Samuelsson B. Leukotrienes: mediators of hypersensitivity reactions and inflammation. Science 1983;220:568-75.

7 Bach MK, Brashler J, Morton D. Solubilization and characterization of the leukotriene $\mathrm{C}_{4}$ synthetase of rat basophil leukaemia cells. A novel particulate glutathione-S-transferase. Arch Biochem 1984;230:455-65.

8 Drazen JM, Austen KF, Lewis RA. Comparative airway and vascular activation of leukotriene $C-1$ and $D$ in vivo and in vitro. Proc Natl Acad Sci USA 1980;77:4354-8.

9 Morris HR, Taylor GW, Piper PJ, Tippins JR. Structure of slow reacting substance of anaphylaxis from guinea pig lung. Nature 1980;285:104-5.

10 Szczeklik A, Gryglewski RJ, Czerniawska-Mysik G. Relationship of inhibition of prostaglandin biosynthesis by analgesics to asthma attacks in aspirin-sensitive patients. analgesics to asth $1975 ; 1: 67-9$

11 Lewis RA, Austen KF, Soberman RJ. Leukotrienes and other products of the 5-lipoxygenase pathway: Biochemistry and relation to pathology in human disease. $N$ Engl f Med 1990;323:645-55.

12 Christie PE, Tagari P, Ford-Hutchinson AW, Charlesson S Chee P, Arm JP, et al. Urinary leukotriene $\mathrm{E}_{4}$ concentrations increase after aspirin challenge in aspirinsensitive asthmatic subjects. Am Rev Respir Dis 1991;143:1025-9.

13 Arm JP, O'Hickey SP, Hawksworth RJ, Fong CY, Crea AEG, Spur BW, et al. Asthmatic airways have a disproportionate hyperresponsiveness to $\mathrm{LTE}_{4}$, as compared with normal airways, but not to $\mathrm{LTC}_{4}, \mathrm{LTD}_{4}$, methacholine and histamine. Am Rev Respir Dis 1990;142:1112-8.

14 Christie PE, Smith CM, Lee TH. The potent and selective sulphidopeptide leukotriene antagonist SK\&F 104353, inhibits aspirin-induced asthma. Am Rev Respir Dis 1991;144:957-8.

15 Dahlen B, Kumlin M, Margolskee DJ, Larsson C, Blomqvist $\mathrm{H}$, Williams VC, et al. The leukotriene-receptor antagonist MK-0679 blocks airway obstruction induced by inhaled lysine-aspirin in aspirin-sensitive asthmatics. Eur Respir $\mathcal{f}$ lysine-aspirin in

16 MacMillan RM, Spree KE, Crawley GC, Walker ERH, Foster SJ. Pre-clinical pharmacology of ICI D2138, a potent orally-active non-redox inhibitor of 5-lipoxygenase. Br f Pharmacol 1992;107:1042-7.

17 Yates RA, MacMillan RM, Ellis SH, Hutchinson M, Culmore EM, Wilkinson DM, et al. A new non-redox 5lipoxygenase inhibitor ICI D2138 is well tolerated and inhibits blood leukotriene synthesis in healthy volunteers. Am Rev Respir Dis 1992;145:A745.

18 Smith CM, Hawksworth RJ, Thien FC, Christe PE, Lee $\mathrm{TH}$. Urinary leukotriene $\mathrm{E}_{4}$ in bronchial asthma. Eur Respir F 1992;5:693-9.

19 Heavey DJ, Soberman RJ, Lewis RA, Spur BW, Austen KF Critical considerations in the development of an assay for sulphidopeptide leukotrienes in plasma. Prostaglandins Leukotrienes Med 1987;33:693-708.

20 Bartels H, Bohmer M, Meirla C. Serum kreatininbestimmung ohne enteweissen. Clin Chim Acta 1972;37:193-7.

21 Carey F, Forder RA. Radioimmunoassay of $\mathrm{LTB}_{4}$ and 6trans $\mathrm{LTB}_{4}$ : analytical and pharmacological characterization of immunoreactive $\mathrm{LTB}_{4}$ in ionophore-stimulated human blood. Prostaglandins Leukotrienes Med 1986;22:57-70.

22 Ferreri NR, Howland WC, Stevenson AD, Spiegelber ML. Release of leukotrienes, prostaglandins and histamine into nasal secretions of aspirin-sensitive asthmatics during reactions to aspirin. Am Rev Respir Dis 1988;137:847-54.

23 Ortolani C, Mirone C, Fontana A, Folco GC, Miadonna A, Montalbetti N, et al. Study of mediators of anaphylaxis in nasal wash fluids after aspirin and sodium metabisulphite nasal provocation in intolerant rhinitic patients. Ann Allergy 1987;59:106-12

24 Bosso JV, Schwartz LB, Stevenson DD. Tryptase and histamine release during aspirin-induced respiratory reactions. $\mathcal{F}$ Allergy Clin Immunol 1991;145:A16.

25 Israel E, Rubin P, Pearlman H, Cohn J, Drazen J. 5 Lipoxygenase inhibition by Zileuton causes acute bronchodilatation in asthma. Am Rev Respir Dis 1992 145:A16.

26 Hui KP, Barnes NC. Lung function improvement in asthma with a cysteinyl-leukotriene antagonist. Lancet 1991;i:1062-3. 
27 Gaddy JN, Margolskee DJ, Bush RK, Williams VC, Busse WW. Broncho-dilatation with a potent and selective leukotriene $\mathrm{D}_{4}\left(\mathrm{LTD}_{4}\right)$ receptor $(\mathrm{MK}-571)$ in patients with asthma. Am Rev Respir Dis 1992;146:358-63.

28 Nasser SM, Bell GS, Hawksworth RJ, Spruce KE, MacMillan $R$, Williams AJ, et al. Effect of the 5-lipoxygenase inhibitor ZD2138 on allergen-induced early and late asthmatic responses. Thorax 1994;49:743-8.

29 Undem BJ, Pickett WC, Lichtenstein LM, Adams GK. The effect of indomethacin on immunologic release of histamine and sulphidopeptide leukotrienes from human bronmine and sulphidopeptide leukotrienes from human bronchus and lung

30 Lee TH, Israel E, Drazen JM, Leitch AG, Ravalese J, Corey EJ, et al. Enhancement of plasma levels of biologically active leukotriene $\mathrm{B}$ compounds during anaphylaxis of guinea pig pretreated by indomethacin or a fish oilenriched diet. $\mathcal{F}$ Immunol 1986;132:2575-82.

31 Knapp HR, Sladek K, Fitzgerald GA. Increased excretion of leukotriene $\mathrm{E}_{4}$ during aspirin-induced asthma. $\mathrm{f} \mathrm{Lab} \mathrm{Clin}$ Med 1992;119:48-51.

32 Kumlin M, Dahlen B, Björck T, Zetterström O, Granström $E$, Dahlen S-E. Urinary excretion of leukotriene $\mathrm{E}_{4}$ and 11dehydro-thromboxane $B_{2}$ in response to bronchial provo- cations with allergen, aspirin, leukotriene $\mathrm{D}_{4}$ and histamine in asthmatics. Am Rev Respir Dis 1992;146:96-103.

33 Christie PE, Tagari P, Ford-Hutchinson AW, Black C, Markendorf A, Schmitz-Schumann $M$, et al. Urinary leukotriene $E_{4}$ after lysine-aspirin inhalation in asthmatic subjects. Am Rev Respir Dis 1992;146:1531-4.

34 Dahlen B, Kumlin M, Johansson H, Larsson C, Zetterström $\mathrm{O}$, Granström E, et al. Aspirin-sensitive asthmatics have elevated basal levels of leukotriene $E_{4}$ in the urine and bronchial provocation with lysine-aspirin results in further release. Am Rev Respir Dis 1991;142:A599.

35 Friedman BS, Bel EH, Buntinx A, Tonaka W, Han Y-HR Shingo S. Oral leukotriene inhibitor (MK886) blocks allergen-induced airway responses. Am Rev Respir Dis allergen-induced

36 Hui KP, Taylor IK, Taylor GW, Rubin P, Kesterson J, Barnes NC, et al. Effect of a 5-lipoxygenase inhibitor on leukotriene generation and airway responses after allergen challenge in asthmatic patients. Thorax 1991;46:184-9.

37 Israel E, Fischer AR, Rosenberg MA, Lilly CM, Callery JC Shapiro J, et al. Pivotal role of 5-lipoxygenase products in the reaction of aspirin-sensitive asthmatics to aspirin. $\mathrm{Am}$ Rev Respir Dis 1993;148:1447-51. 